\title{
A Review of Influential Factors Affecting Undergraduate Students' Creative Thinking
}

\author{
Puthyrom Tep ${ }^{1}$, Sorakrich Maneewan ${ }^{2}$, Saranya Chuathong ${ }^{3}$, Matthew A. Easter ${ }^{4}$ \\ ${ }^{1}$ Learning Innovation and Technology Program, King Mongkut's University of Technology Thonburi, Bangkok, Thailand, \\ puthyrom.tep@mail.kmutt.ac.th \\ ${ }^{2}$ Department of Educational Communications and Technology, King Mongkut's University of Technology Thonburi, \\ Bangkok, Thailand, sorakrich.man@kmutt.ac.th \\ ${ }^{3}$ Department of Educational Communications and Technology, King Mongkut's University of Technology Thonburi, \\ Bangkok, Thailand, saranya.chu@kmutt.ac.th \\ ${ }^{4}$ Educational, School, \& Counseling Psychology, University of Missouri, Columbia, Missouri, EasterMA@missouri.edu
}

\begin{abstract}
Creative thinking was listed among the skills that are required for upcoming graduating students' entry-level careers which become more important to global industries. Due to the importance of this concept, the need to investigate undergraduate students' creative thinking has been rising. This article presents an overview of influential factors on undergraduate students' creative thinking. The influential factors were reviewed in two main aspects - contextual and individual levels. Researchers have investigated the relationship between educational setting and parental factors affecting creative thinking in the contextual aspect, while in the individual level aspect, researcher has investigated the relationship between intelligence and personality affecting creative thinking. Based on various recent studies and related theories, key factors that influence undergraduate students' creative thinking are outlined along with a proposed conceptual framework. In the future, establishing and testing the proposed conceptual framework in terms of defining the influential paths and key factors affecting creative thinking will be conducted.
\end{abstract}

KEYWORDS: Creative thinking, Educational setting, Intelligence, Parental factors, Personality

\section{Introduction}

Developments in genetics, artificial intelligence, robotics, nanotechnology, 3D printing, biology, and other fields are all building on each other (World Economic Forum 2016) with impacts all over the globe. While these developments have brought about innumerable positive changes, they are also creating complex business, political, technological, health and environmental challenges (Partnership for 21st Century Skills 2008), leading to complicated problems that include global warming, pollution, financial crises, and new epidemics (Lau, John, and Sons 2015). Consequently, such complicated and varied matters in our rapidly changing surroundings demand creative, adoptable solutions. The more ideas one has, the more solutions will be at one's disposal, while new ideas can open up new worlds, new insights, and new ways of doing old things (VanGundy 2005). Creativity, therefore, can help people reinvent themselves and their organizations (VanGundy 2005). As Simone and Nel (2016) noted, creative thinking's effects are widespread. It offers us the opportunity to go outside our universe, produce artwork, create electronic devices, and treat diseases. Moreover, to survive in a fast-changing world, we also reasonably require suitable thinking skills that can help us make wise decisions and rapidly gain new knowledge (Lau, John, and Sons 2015). In addition, institutions require creative standpoints and solutions to develop new products, services, processes, marketing strategies, and ways of managing and using resources (VanGundy 2005). Creativity is like a spell of enchantment that can change an organization, company, division, or department (Lau, John, and Sons 2015). However, encouraging this potential mental ability usually is underdeveloped (VanGundy 2005).

According to para-academic organizations such as P21 (Partnership for 21st Century Skills 2008), there are 4 competencies to position and develop in a changing learning society. P21 promotes the $4 \mathrm{Cs}$ as a framework for $21 \mathrm{st}$ Century Learning, in multiple areas including communication, collaboration, critical thinking and creativity. Indeed, creativity and creative thinking are still prominent in skill frameworks (Lai et al. 2017) and can be considered one of the key competencies for the twenty-first century (Simone and Nel 2016). In the same vein, the World Economic Forum Future of Jobs Report highlights the 10 top skills that will be needed for students and workers in the digital and transdisciplinary world of tomorrow. By 2020, these competencies should include the ability to solve complex problems, critical thinking, creativity, ability to 
coordinate with others, negotiation, cognitive flexibility and emotional intelligence. Therefore, educators and institutions should expend more effort towards improving upcoming graduating students' creative thinking, which is one of the skills required for startup careers (Wu, Siswanto, and Ko 2017) and starts to be essential for global industries, for their success and to catch up with current and future trends.

Nowadays, the way people perceive their own creativity has become a growing area of research (Hass, Katz-Buonincontro, and Reiter-Palmon 2016). Having said that, research related to creativity has captured enlarged attention and has been prioritized (Runco 2004). For instance, from 2001 to 2006 there were more than 200 theses and journal articles written and published pertaining to creativity in Taiwan ( $\mathrm{Li}$ and $\mathrm{Wu} 2011$ ). As creativity grows as a topic of research, researchers have used many different perspectives to develop various models of measuring creativity (Batey and Furnham 2006). Kālis, Roķe, and Krūmiņa (2013) stated that assessment of creativity should focus on creative potential more than creative people because creativity in the context of individuals was difficult to measure (Piffer 2012). In the motivational perspective, Hass, Katz-Buonincontro, and Reiter-Palmon (2016) investigated the fixed and growth creative mindsets, and their relationship to creative self-efficacy and creative identity. Furthermore, in the process-centered view, Rojas and Tyler (2018) and Tan and Teo (2017) examined the psychometric measurement of creativity in the aspect of creative process.

For decades, the factors affecting creative thinking have been the focus of many studies in many diverse perspectives (Verhaeghen, Trani, and Aikman 2017; Sarsani 2007; Chen 2016; Boonchan, Pupat, and Seesan 2017; Jankowska et al. 2018; Moltafet, Sadati Firoozabadi, and PourRaisi 2018; Yamaguchi and Sannomiya 2012). Verhaeghen, Trani, and Aikman (2017) investigated the relationship between creativity (interest, behavior and abilities) and different aspects of thought patterns. Sarsani (2007) conducted a survey with 373 students from India in order to explore the relationship between creativity and organizational or school variables, students' personal background variables, and cognitive and motivational variables. Similarly, Moltafet, Sadati Firoozabadi, and Pour-Raisi (2018) also conducted research with 3,372 undergraduate students in India, in which they sought to examine the relationship between parental styles and emotional creativity. They also investigated the mediating role of the fulfillment of basic psychological needs in this relationship. Chen (2016) studied the association between personality and everyday creativity and put more effort on examining how conscientiousness influences creativity among Chinese undergraduate students. Boonchan, Pupat, and Seesan (2017) developed a causal model by selecting variables affecting undergraduate students' creativity such as administration, teaching, instructional climate, motivation, and personality. Jankowska et al. (2018) also thoroughly investigated the relationship between subclinical autistic traits, cognitive (performance-based) and personalityrelated (self-reported) creativity. Furthermore, Yamaguchi and Sannomiya (2012) examined beliefs and attitudes towards creativity among Japanese university students. This article will present an overview of influential factors of undergraduate students' creative thinking. The influential factors will be reviewed in two main aspects - contextual and individual levels. In the contextual aspect, researchers have investigated the relationship between educational settings and parental factors affecting creative thinking, while in the individual level aspect, researchers have investigated the relationship between intelligence and personality affecting creative thinking.

\section{Creativity and Creative Thinking}

There is still considerable debate on the precise definition of creativity and creative thinking (Corazza and Agnoli 2016). According to Barbot, Besançon, and Lubart (2016), creativity typically is the consequences of creative thinking. With this in mind, Corazza and Agnoli (2016) stated that these two terms closely correspond to each other and can be used interchangeably. If this is the case, cultivating the ability to think creatively among students is equivalent to fostering creativity, which many researchers concentrate on in academic settings (Miller and Dumford 2015; $\mathrm{Hu}, \mathrm{Wu}$, and Shieh 2016; Garaigordobil and Berrueco 2011). As a matter of fact, possibly because of ambiguous nature of creative thinking, there is no common agreement as to what defines creative thinking (Runco 2004). 
Furthermore, creative thinking involves creating ideas to address problems using techniques such as brainstorming and visualization (Ruggiero 2003; McArdle 2018). Creative thinking has been defined as: (1) creating unique and original approaches to problem solving (Guilford 1956; Harris 2014; Saccardi 2014) and is required in order to develop innovative ideas for problem resolution (Lau, John, and Sons 2015); (2) a process that creators use to generate novel and valuable ideas, solutions, or products that still do not exist (Sarkar and Chakrabarti 2011); (3) involving characteristics such as cognition, personality, environment, and motivation, and the positioning of outcomes in the context of a wide knowledge domain (Black, Freeman, and Stumpo 2015); (4) an incidental occurrence, which does not have a very clear early goals of creating elaborated plans and processes (He 2017); (5) an intentional occurrence, the complete opposite of the incidental, that has a clear goal (He 2017); (6) creating new ideas, new strategies and developing approaches to performing tasks in order to obtain more productive results (Wong and Cheung 2011). As a means to synthesize these various views, creativity or creative thinking in this paper refers to the ability to generate new ideas and concepts, and the ability to think divergently and productively in an academic domain.

\section{Conceptual Framework}

Undergraduate students need to study well for their upcoming careers, and with this in mind, they require active creative thinking (Wu, Siswanto, and Ko 2017). As such, an overall conceptual framework to understand and assess undergraduate creative thinking is important to consider. Such a framework is presented in Figure 1 below. This framework considers both individual level and environmental level factors. The contextual aspect is comprised of educational settings and parental factors while the individual level aspects consist of intelligence and personality factors that affect creative thinking. What follows is a discussion of this proposed conceptual framework and its utility in better understanding and fostering undergraduate creative thanking.

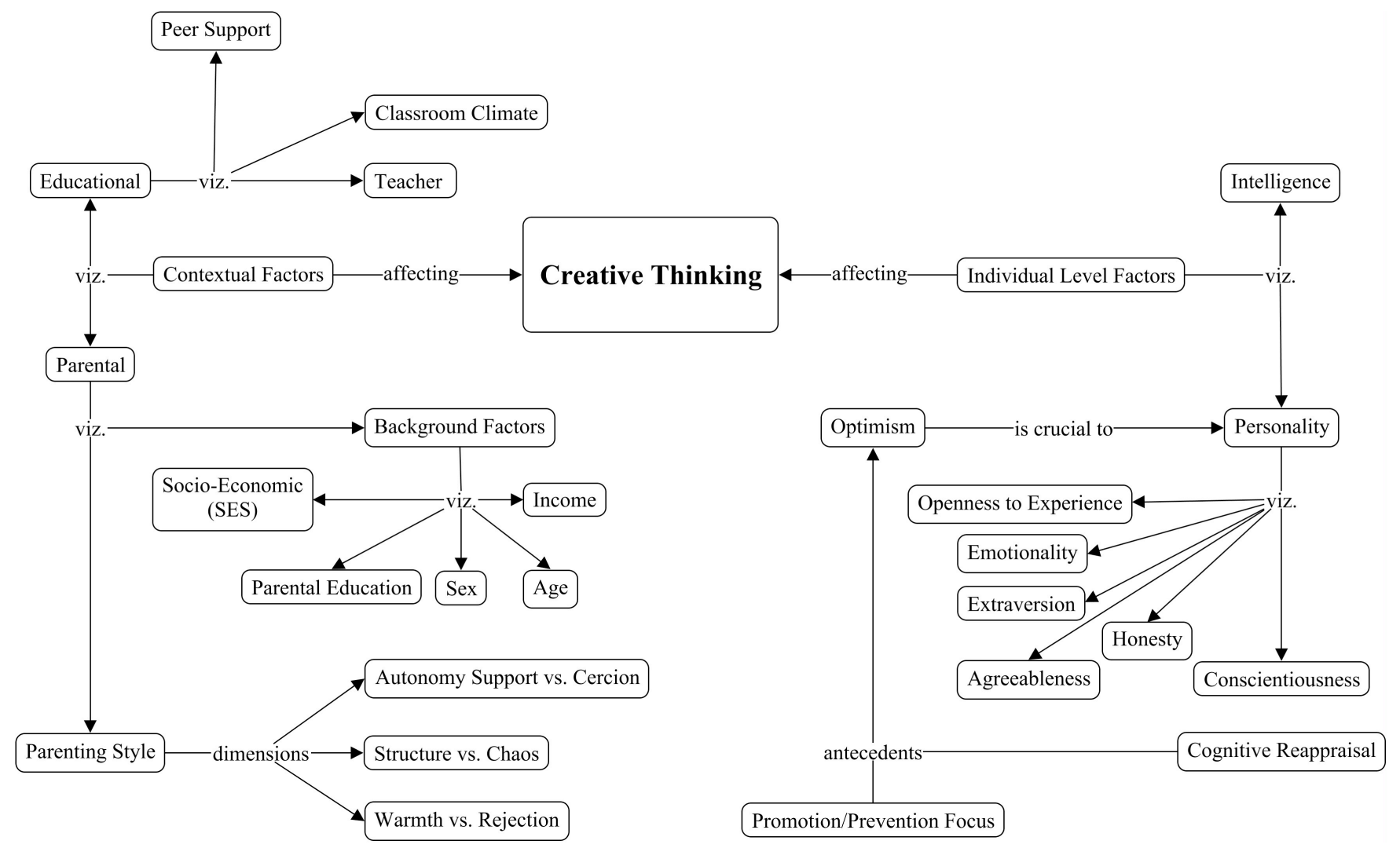

Figure 1. The Conceptual Framework 


\section{Factors affecting creative thinking of undergraduate students}

\subsection{Contextual Factors}

\subsubsection{Educational-Oriented Factors}

To develop the creativity of adolescents, educational system require considerable expansion, and in this system, teachers are one of the essential components (Craft 2009; Davies 2006). Teachers are also defined as being in a particular position to be one of the important factors in impacting students' development (Bingham and Okagaki 2012; Li 2018). Davies et al. (2014) identified the creative learning environment which aims to promote creativity in students as illustrated in two perspectives - the physical and pedagogical environments. Teachers were recognized as one of the main elements in the pedagogical environment that prioritized the extent to which they prepare for teaching and learning (Davies et al. 2014). According to recent research on teachers and creativity, teachers should possess strong intrapersonal awareness (Reilly et al. 2011), teacher skills needed (Wood and Ashfield 2008) and role model of creative behaviors (Jeffrey 2006).

To bring out the highest level of student's creativity as much as possible, one should think about the influence and domination of classroom environment (Amabile 1998). Correspondingly, everything that happens in the classroom, eventually will be important to students' creative thinking (Beghetto and Kaufman 2014). Hennessey (2004) stated that the interaction between student and environment with the nearest suitable point may foster students' creativity. According to Florida (2014), classrooms should provide a more broad-minded and independent learning environment. Thus, the classroom environment has significant effects on students, so it should operate carefully and deliberately.

From the student's perspective, there are many elements that stimulate creativity, including the support of peers (Zhou and Valero 2016). Peer support within small groups brings about interaction between members and supports the accountable to creativity (Horng et al. 2005). Sternberg (1994) indicated that personal and professional relationships with peers help students' creativity and even career assists in development.

All things consider in the context of educational-oriented factors, the way that teachers prepare for teaching and learning, classroom environment where students can express their ideas freely and support of peers within small group may lead to fostering undergraduate students' creative thinking. As such, the proposed conceptual framework for undergraduate students' creative thinking may include teacher, classroom climate and peer support factors.

\subsubsection{Parental-Oriented Factors}

Parenting style refers to the methods that parents use in order to take care of their children while they are growing up and as well as the responsibility of parents' attitudes and belief in the family context (Darling and Steinberg 1993). Parenting styles have been grouped into different categories (Buri 1991; Schaefer 1959). According to Baumrind (1991), there are three parenting styles: authoritarian, permissive, and authoritative. Moreover, Skinner, Johnson, and Snyder (2005) intensively reviewed literature pertaining to how to measure parenting style. They identified six components such as warmth vs. rejection, structure vs. chaos, and autonomy support vs. coercion. Recent research shows that parenting styles seem to play an important role affecting creativity of students (Mehrinejad, Rajabimoghadam, and Tarsafi 2015; Fearon, Copeland, and Saxon 2013; Miller, Lambert, and Speirs Neumeister 2012). There is an agreement by researchers (Mehrinejad, Rajabimoghadam, and Tarsafi 2015; Fearon, Copeland, and Saxon 2013; Miller, Lambert, and Speirs Neumeister 2012) that authoritarian parenting style showed negative affect on creativity. Moreover, the study of Mehrinejad, Rajabimoghadam, and Tarsafi (2015) indicated that authoritative parenting style showed positive relationship toward creativity. Nonetheless, Miller, Lambert, and Speirs Neumeister (2012)'s study suggested that there is a positive relationship between permissive parenting style and creativity.

In addition, creativity among adolescents is an incorporated function of intelligent, socioeconomic status (SES) and gender (Sharma as cited in Sarsani 2007). However, some studies reveal 
that there is no significant difference in creativity and SES (Jarial and Sharma 1980). Students who had well-educated parents attained a high score in creativity, thus, the father and mother's education fostered the creative thinking ability of their children (Sudhir Kumar as cited in Sarsani 2007). Furthermore, background factors like type of family and number of siblings also could influence the creativity of students (Sharma as cited in Sarsani 2007).

Notably, authoritative parenting style may influent creative thinking of undergraduate students whereas parenting background such as SES also was found significant too. As such, the proposed conceptual framework for undergraduate students' creative thinking may include parenting style and their background factors.

\subsection{Individual Level Factors}

\subsubsection{Intelligence}

According to McKay, Karwowski, and Kaufman (2017), The Amusement Park Theoretical model (Baer and Kaufman 2005) argued that intelligence is an important factor for creativity. An appropriate degree of cognitive functioning is essential to learn across multiple domains of creativity (McKay, Karwowski, and Kaufman 2017). Jauk, Benedek, and Neubauer (2013) demonstrated the association between intelligence and creative achievement in general and proposed two reasons for how intelligence plays important role in creativity, first, the association between intelligence and ideational originality (normal cognitive mechanisms focus on divergent and convergent thinking processes), second, creativity achievement may present the huge and complicated tasks which depend upon intelligence. Jauk, Benedek, and Neubauer (2013) also demonstrated the complex association between intelligence and creative ability. Hence, the studies show consensus on the relationship between intelligence and creativity, which means that intelligence is considered influential on creativity.

\subsubsection{Personality}

The personality of individuals causes the production of creative thoughts (Amabile 1996; Guilford 1971). One of personality theory that was widely used to study is The Big Five personality traits (Goldberg 1992; John and Srivastava 1999) or the Five-Factor personality traits (McCrae and Costa 1987). According to Kyllonen, Walters, and Kaufman (2005), the Five-Factor personality traits suggests that most individual differences in human personality can be classified into five dimensions: neuroticism (or conversely emotional stability), extraversion, openness to experience, conscientiousness, and agreeableness. The Five-Factor Model, or Big Five, offers a helpful classification of personality traits, moreover, these traits anticipate many important life consequences, that is, students' achievement and employment, healthy mind and body (Ozer and Benet-Martínez 2005). Result from many studies shows that openness to experience is the only factor that consistently and broadly related to creativity (Batey and Furnham 2006; Silvia 2008; Nusbaum and Silvia 2011). Openness to experience is connected intimately with all measures of creativity (Kerr and McKay 2013). In addition, according to McKay, Karwowski, and Kaufman (2017), people high in openness to experience personality trait are interested in creative activities.

Coupled with personality traits, Optimism was defined as positive outcome expectations and confrontation with setbacks ( $\mathrm{Li}$ as cited in $\mathrm{Li}$ and $\mathrm{Wu} 2011$ ). Optimists always produce positive thinking toward the future and believe that they overcome any obstacles ( $\mathrm{Li}$ and $\mathrm{Wu} 2011$ ). Li and $\mathrm{Wu}$ (2011) conducted research optimism and found that optimism is crucial to the creative personality, which is compatible with Chen et al.'s (1996) as cited in Li and Wu (2011) proposition and proposed a future research on understanding the role of optimism and its influence on creativity.

Based on the finding that intelligence forms relationship with creativity and personality of individuals affects the creation of creative thought, as such, the proposed conceptual framework for undergraduate students' creative thinking may consider the intelligence and personality of individuals, such as openness to experience, as the influential factors. 


\section{Conclusions}

Creative thinking was listed among the skills required for upcoming graduating students' entry-level careers which become more important to global industries. Due to the importance of this concept, the need to investigate undergraduate students' creative thinking has been rising. This article reviewed the influential factors of undergraduate students' creative thinking and proposed a model categorizing two main aspects - contextual and individual level factors. Based on various studies, we see that key contextual aspect to consider are educational setting and parental factors, while individual level aspects include to consider are intelligence and personality in terms of influencing creative thinking.

Future research will focus on establishing and testing the proposed conceptual framework in terms of further defining the influential paths and the other possible key factors affecting creative thinking.

\section{References}

Amabile, Teresa. 1996. Creativity in context update to the social psychology of creativity. Boulder, Colo: Westview Press.

Amabile, Teresa. 1998. How to kill creativity. Boston, MA: Harvard Business School Publishing.

Baer, John, and James C. Kaufman. 2005. 'Bridging generality and specificity: The amusement park theoretical (APT) model of creativity.' Roeper Review 27: 158-63.

Barbot, Baptiste, Maud Besançon, and Todd Lubart. 2016. 'The generality-specificity of creativity: Exploring the structure of creative potential with EPoC.' Learning and Individual Differences 52: 178-87.

Batey, Mark, and Adrian Furnham. 2006. 'Creativity, Intelligence, and Personality: A Critical Review of the Scattered Literature.' Genetic, social, and general psychology monographs 132: 355.

Baumrind, Diana. 1991. 'The Influence of Parenting Style on Adolescent Competence and Substance Use.' The Journal of Early Adolescence 11: 56-95.

Beghetto, Ronald A., and James C. Kaufman. 2014. 'Classroom contexts for creativity.' High Ability Studies High Ability Studies 25: 53-69.

Bingham, Gary E., and Lynn Okagaki. 2012. 'Ethnicity and Student Engagement'.

Black, Catherine, Charles Freeman, and Gordon Stumpo. 2015. 'Conceptual model and strategies for creative thinking in apparel design.' International Journal of Fashion Design, Technology and Education 8: 131-38.

Boonchan, Banjob, Phadungchai Pupat, and Boonchan Seesan. 2017. 'Causal Model of Variables Affecting the Creativity of Undergraduate Students.' Creative Education, 8(2): 15.

Buri, John R. 1991. 'Parental Authority Questionnaire.' Journal of Personality Assessment 57: 110-19.

Chen, Bin-Bin. 2016. 'Conscientiousness and everyday creativity among Chinese undergraduate students.' Personality and Individual Differences 102: 56-59.

Corazza, Giovanni Emanuele, and Sergio Agnoli. 2016. 'On the Path Towards the Science of Creative Thinking.' in Giovanni Emanuele Corazza and Sergio Agnoli (eds.), Multidisciplinary Contributions to the Science of Creative Thinking. Singapore: Springer Singapore.

Craft, Anna. 2009. Creativity in schools: tensions and dilemmas. London: Routledge.

Darling, Nancy, and Laurence Steinberg. 1993. 'Parenting style as context: An integrative model.' Psychological Bulletin 113: 487-96.

Davies, Dan, Divya Jindal-Snape, Rebecca Digby, Alan Howe, Christopher Collier, and Penny Hay. 2014. 'The roles and development needs of teachers to promote creativity: A systematic review of literature.' Teaching and Teacher Education 41: 34-41.

Davies, Trevor. 2006. 'Creative teaching and learning in Europe: promoting a new paradigm.' The Curriculum Journal 17: $37-$ 57.

Fearon, Danielle D., Daelynn Copeland, and Terrill F. Saxon. 2013. 'The Relationship Between Parenting Styles and Creativity in a Sample of Jamaican Children.' Creativity Research Journal 25: 119-28.

Florida, Richard. 2014. 'The Creative Class and Economic Development.' Economic Development Quarterly 28: 196-205.

Garaigordobil, Maite, and Laura Berrueco. 2011. 'Effects of a Play Program on Creative Thinking of Preschool Children.' The Spanish journal of psychology 14: 608-18.

Goldberg, Lewis R. 1992. 'The development of markers for the Big-Five factor structure.' Psychological Assessment 4: $26-42$.

Guilford, J. P. 1971. The nature of human intelligence. London: McGraw-Hill.

Guilford, Joy Paul. 1956. 'The structure of intellect.' Psychological Bulletin Psychological Bulletin 53: 267-93.

Harris, La Verne Abe. 2014. Idea engineering : creative thinking and innovation. New York: Momentum Press.

Hass, Richard W., Jen Katz-Buonincontro, and Roni Reiter-Palmon. 2016. 'Disentangling creative mindsets from creative self-efficacy and creative identity: Do people hold fixed and growth theories of creativity?' Psychology of Aesthetics, Creativity, and the Arts 10: 436-46.

He, Kekang. 2017. 'A theory of creative thinking: construction and verification of the dual circulation model.'

Hennessey, Beth A. 2004. Developing creativity in gifted children: the central importance of motivation and classroom climate. Storrs, CT: National Research Center on the Gifted and Talented, University of Connecticut. 
Horng, Jeou-Shyan, Jon-Chao Hong, Lih-Juan ChanLin, Shih-Hui Chang, and Hui-Chuan Chu. 2005. 'Creative teachers and creative teaching strategies.' International Journal of Consumer Studies 29: 352-58.

$\mathrm{Hu}$, Ridong, Yi-Yong Wu, and Chich-Jen Shieh. 2016. 'Effects of Virtual Reality Integrated Creative Thinking Instruction on Students' Creative Thinking Abilities.' Eurasia Journal of Mathematics, Science and Technology Education 12: 47786.

Jankowska, D. M., I. Omelańczuk, M. Czerwonka, and M. Karwowski. 2018. 'Exploring links between creative abilities, creative personality and subclinical autistic traits.' Personality and Individual Differences.

Jarial, Gurpal S., and A. K. Sharma. 1980. 'Creativity and its components as affected by intelligence, personality and their interaction.' Asian Journal of Psychology \& Education 6: 26-32.

Jauk, Emanuel, Mathias Benedek, and Aljoscha C. Neubauer. 2013. 'The Road to Creative Achievement: A Latent Variable Model of Ability and Personality Predictors.' European Journal of Personality 28: 95-105.

Jeffrey, Bob. 2006. 'Creative teaching and learning: towards a common discourse and practice.' Cambridge Journal of Education 36: 399-414.

John, Oliver P., and Sanjay Srivastava. 1999. 'The Big Five Trait taxonomy: History, measurement, and theoretical perspectives.' Handbook of personality: Theory and research, 2nd ed. New York, NY: Guilford Press.

Kālis, Emīls, Līga Roķe, and Indra Krūmiņa. 2013. 'Indicators of Creative Potential in Drawings: Proposing New Criteria for Assessment of Creative Potential the Test for Creative Thinking - Drawing Production.' Baltic Journal of Psychology 14: 22-37.

Kerr, Barbara, and Robyn McKay. 2013. 'Searching for Tomorrow's Innovators: Profiling Creative Adolescents.' Creativity Research Journal 25: 21-32.

Kyllonen, Patrick, Alyssa M. Walters, and James C. Kaufman. 2005. 'Noncognitive Constructs and Their Assessment in Graduate Education: A Review' Educational Assessment 10: 153-84.

Lai, Emily, Kristen DiCerbo, Peter Foltz, Pearson, and P. 2017. Skills for Today: What We Know about Teaching and Assessing Collaboration (Pearson. One Lake Street, Upper Saddle River, New Jersey 07458. Website: http://www.pearsoned.com/).

Lau, Joe Y. F., Wiley John, and Sons. 2015. An introduction to critical thinking and creativity: think more, think better. Hoboken, N.J.: John Wiley \& Sons.

Li, Cheng-Hsien, and Jing-Jyi Wu. 2011. 'The Structural Relationships Between Optimism and Innovative Behavior: Understanding Potential Antecedents and Mediating Effects.' Creativity Research Journal 23: 119-28.

Li, Yongmei. 2018. 'Teacher-Student Relationships, Student Engagement, and Academic Achievement for Non-Latino and Latino Youth.' Adolescent Research Review 3: 375-424.

McArdle, Karen. 2018. 'Freedom Research in Education: Becoming an Autonomous Researcher.'

McCrae, Robert R., and Paul T. Costa. 1987. 'Validation of the five-factor model of personality across instruments and observers.' Journal of Personality and Social Psychology 52: 81-90.

McKay, Alexander S., Maciej Karwowski, and James C. Kaufman. 2017. 'Measuring the muses: Validating the Kaufman Domains of Creativity Scale (K-DOCS).' Psychology of Aesthetics, Creativity, and the Arts 11: 216-30.

Mehrinejad, Seyed Abolghasem, Sara Rajabimoghadam, and Mahdieh Tarsafi. 2015. 'The Relationship between Parenting Styles and Creativity and the Predictability of Creativity by Parenting Styles.' Procedia - Social and Behavioral Sciences 205: 56-60.

Miller, Angie L., and Amber D. Dumford. 2015. 'The Influence of Institutional Experiences on the Development of Creative Thinking in Arts Alumn.' Studies in Art Education 56: 168-82.

Miller, Angie L., Amber D. Lambert, and Kristie L. Speirs Neumeister. 2012. 'Parenting Style, Perfectionism, and Creativity in High-Ability and High-Achieving Young Adults.' Journal for the Education of the Gifted 35: 344-65.

Moltafet, Ghavam, Somayeh Sadat Sadati Firoozabadi, and Asieh Pour-Raisi. 2018. 'Parenting Style, Basic Psychological Needs, and Emotional Creativity: A Path Analysis.' Creativity Research Journal 30: 187-94.

Nusbaum, Emily C., and Paul J. Silvia. 2011. 'Are Openness and Intellect distinct aspects of Openness to Experience? A test of the O/I model' Personality and Individual Differences 51: 571-74.

Ozer, Daniel J., and Verónica Benet-Martínez. 2005. 'Personality and the Prediction of Consequential Outcomes.' Annual Review of Psychology 57: 401-21.

Partnership for 21st Century Skills. 2008. 21St Century Skills, Education \& Competitiveness: A Resource andPolicy Guide.

Piffer, Davide. 2012. 'Can Creativity Be Measured? An Attempt to Clarify the Notion of Creativity and General Directions for Future Research.' Thinking Skills and Creativity 7: 258-64.

Reilly, Rosemary C., Frank Lilly, Gillian Bramwell, and Neomi Kronish. 2011. 'A synthesis of research concerning creative teachers in a Canadian context.' Teaching and Teacher Education 27: 533-42.

Rojas, J. P., and K. M. Tyler. 2018. 'Measuring the Creative Process: A Psychometric Examination of Creative Ideation and Grit.' Creativity Research Journal 30: 29-40.

Ruggiero, Vincent Ryan. 2003. Making your mind matter: strategies for increasing practical intelligence. Lanham: Rowman \& Littlefield.

Runco, Mark A. 2004. 'Creativity.' Annual Review of Psychology 55: 657-87.

Saccardi, Marianne. 2014. Creativity and children's literature : new ways to encourage divergent thinking.

Sarkar, Prabir, and Amaresh Chakrabarti. 2011. 'Assessing design creativity.' Design Studies 32: 348-83.

Sarsani, Mahender Reddy. 2007. 'A Model for the Correlates of Students' Creative Thinking.' Journal on School Educational Technology 2: 35-48. 
Schaefer, Earl S. 1959. 'A circumplex model for maternal behavior.' The Journal of Abnormal and Social Psychology 59: 226-35.

Silvia, Paul J. 2008. 'Another look at creativity and intelligence: Exploring higher-order models and probable confounds.' Personality and Individual Differences 44: 1012-21.

Simone, M. Ritter, and Mostert Nel. 2016. 'Enhancement of Creative Thinking Skills Using a Cognitive-Based Creativity Training.' Journal of Cognitive Enhancement 1-11.

Skinner, Ellen, Sandy Johnson, and Tatiana Snyder. 2005. 'Six Dimensions of Parenting: A Motivational Model.' Parenting 5: 175-235.

Sternberg, Robert J. 1994. Encyclopedia of human intelligence. New York; Toronto: Macmillan; Maxwell Macmillan Canada; Maxwell Macmillan International.

Tan, Chee-Seng, and Timothy Teo. 2017. 'Psychometric qualities of the Creative Process Engagement Scale in a Malaysian undergraduate sample.' Swiss Journal of Psychology 76: 35-42.

VanGundy, Arthur. 2005. 101 activities for teaching creativity and problem solving. San Francisco: Jossey-Bass.

Verhaeghen, P., A. N. Trani, and S. N. Aikman. 2017. 'On Being Found: How Habitual Patterns of Thought Influence Creative Interest, Behavior, and Ability.' Creativity Research Journal 29: 1-9.

Wong, Chi-Sum, and Millissa F. Y. Cheung. 2011. 'Transformational leadership, leader support, and employee creativity.' Leadership \& Organization Development Journal 32: 656-72.

Wood, Ruth, and Jean Ashfield. 2008. 'The use of the interactive whiteboard for creative teaching and learning in literacy and mathematics: a case study.' British Journal of Educational Technology 39: 84-96.

World Economic Forum. 2016. The future of jobs employment, skills and workforce strategy for the fourth industrial revolution.

Wu, Mingchang, Ibnu Siswanto, and Chenju Ko. 2017. 'The influential factors and hierarchical structure of college students' creative capabilities-An empirical study in Taiwan.' Thinking Skills and Creativity 26: 176-85.

Yamaguchi, Yosuke, and Machiko Sannomiya. 2012. 'Beliefs and Attitudes About Creativity Among Japanese University Students.' Creativity \& Human Development 14: 1-11.

Zhou, Chunfang, and Paola Valero. 2016. 'A Comparison of Creativity in Project Groups in Science and Engineering Education in Denmark and China.' in Giovanni Emanuele Corazza and Sergio Agnoli (eds.), Multidisciplinary Contributions to the Science of Creative Thinking. Singapore: Springer Singapore. 